\title{
Reliable estimation of dietary exposure to furan from coffee: An automatic vending machine as a case study
}

\author{
M. Mesías, F.J. Morales
}

Institute of Food Science, Technology and Nutrition, ICTAN-CSIC, José Antonio Novais 10, 28040 Madrid, Spain

\begin{abstract}
Worldwide Food Safety Agencies have classified furan as carcinogenic and cytotoxic due to its effects in animal studies, and it has been associated with harmful effects to human health. It has been pointed out that coffee consumption is the major contributor to dietary furan exposure for adults. However, furan is highly volatile and its losses due to volatilization in the cup during the time expend to consume the coffee brew should be taken into account for a realistic estimation of the levels of furan exposure for humans. The aim of this study was to estimate the furan exposure to humans considering the time for consumption after preparation of the fresh beverage. Furan was determined in coffee brews acquired from automatic coffee vending machines placed in areas with high density of population. Furan levels in coffee beverages ranged from I I to $262 \mathrm{ng} / \mathrm{mL}$ (mean = I7I \pm 59.8). Furthermore, five different scenarios were settled immediately after the acquisition of coffee brews from the coffee vending machines in order to assess a realistic estimation of furan exposure. Furan content in coffee decreased from 170 up to $4 \mathrm{ng} / \mathrm{mL}$ after simulating the behavior of coffee consumption ( $74 \%$ after standing at room temperature for $5 \mathrm{~min}, \sim 64 \%$ after stirring for $30 \mathrm{~s}$ and standing at room temperature up to $5 \mathrm{~min}, \sim 94 \%$ after stirring for $5 \mathrm{~min}, \sim 97 \%$ after $8 \mathrm{~h}$ in a sealed thermo and $\sim 37 \%$ after being cooled one week at a fridge). These results suggest that it is mandatory to establish very precisely the furan levels in the final ready-to-drink beverage in order to obtain reliable estimations of the daily intake from coffee and to define potential strategies for mitigation. Furan intake from coffee ranged from 0.02 to $0.43 \mu \mathrm{g} / \mathrm{kg}$ b.w./day, resulting in a mean exposure of $0.31 \mu \mathrm{g} / \mathrm{kg}$ b.w./day.
\end{abstract}

KEYWORDS: Furan, Coffee, Exposure, Processing contaminants, Food safety, HS GC-MS.

\section{INTRODUCTION}

Furan is a volatile compound present in many foods and drinks as a result of thermal treatment during processing. High concentrations of this compound have been described in baked and roasted products, as well as in foods subjected to retorting in cans and jars, probably due to volatiles being trapped in food containers (EFSA, 2004). The occurrence of furan is related to the flavor of food products, providing pleasant characteristics. However, it has also been associated with toxic and genotoxic effects and, therefore, furan exposure is a human health concern. Carcinogenic and cytotoxic properties have been evidenced in experimental animals and furan has been classified as possibly carcinogenic to humans (Group 2B) by the International Agency for Research on Cancer (IARC, 1995). For that reason, in recent years this compound has received special attention from Food Safety Agencies and data on furan concentrations in commercial food products have been collected. In addition, technological strategies in order to prevent or mitigate furan formation in foods and, furthermore, to remove the already formed furan from the food product have been performed (EFSA, 2010; FAO/WHO, 2010; US FDA, 2004).

It has been estimated that coffee consumption may be the highest contributor to furan exposure from dietary sources for adults (EFSA, 2009; Mesías, Guerra-Hernandez, \& Garcia-Villanova, 2012; Morehouse, Nyman, McNeal, Dinovi, \& Perfetti, 2008). Furan is present in coffee as part of the volatile aroma 
components generated during roasting (Merritt, Bazinet, Sullivan, \& Robertson, 1963); thus, furan concentrations are very low or not detected in green coffee, whereas levels up to $7000 \mu \mathrm{g} / \mathrm{kg}$ have been observed in roasted ground coffee (Guenther, Hoenicke, Biesterveld, Gerhard-Rieben, \& Lantz, 2010). During roasting, furan formation depends on green coffee varieties and roasting conditions (Altaki, Santos, \& Galceran, 20II; Guenther et al., 2010; Zoller, Sager, \& Reinhard, 2007). From roasting to the cup furan levels decrease due to the high volatility and low water solubility of furan. Thus, through grinding, packed, storage and brewing procedure furan losses are produced. Grinding procedures may generate furan losses of about $50 \%$, influenced by the final particle size of ground coffee (Guenther, 20I2) whereas losses of about $25 \%$ have been described in coffee packs stored at room temperature, compared to the levels observed at first opening. In addition, 50-60\% of furan in the roast and ground coffee can be lost in the brewing process (Guenther et al., 2010), the furan concentration in the coffee brew being influenced by the coffee preparation, brewing temperature, coffee/water ratio, contact times and brewer types (Petraco, 2005). Ultimately, furan can be partially evaporated in the cup during consumption time, normally because coffee from brewing is too hot and consumers wait until the beverage cools down (Guenther, 2012). Therefore, since furan losses are produced after brewing and prior to consumption, more reliable data about furan Consumption from coffee are required to assess the exposure of humans to furan.

The aim of this study was to determine furan levels in coffee beverages acquired from coffee vending machines, having an important contribution to the coffee consumed outside home. This research has been intentionally limited to commercially available automatic coffee machines placed in important walkway areas such as hospitals, train or bus stations and universities to estimate the exposure in real conditions better than use pilot plant equipment. This investigation is not aimed to optimize the technical features of processing in coffee vending machines. In addition, discussion on furan stability in coffee brew and, therefore, their impact on levels of furan exposure to humans is pointed out.

\section{MATERIALS AND METHODS}

\section{Chemicals}

5-Caffeoylquinic acid, hydroxymethylfurfural (HMF) and furan were purchased from Sigma-Aldrich (St Louis, MO, USA), caffeine and furfural from Fluka (Madrid, Spain) and furan-d4 from Isotec (Ohio, USA). Purity of furan and furan-d4 was $\geq 99 \%$ and $98 \%$, respectively. Glacial acetic and formic acid were acquired from Merck (Darmstadt, Germany). HPLC grade methanol and acetonitrile were purchased from Merck (Darmstadt, Germany). All other chemicals used were of analytical grade. Demineralized water was obtained by filtering distilled water through a Milli-Q Ultrapure Water System (Millipore, Bedford, MA, USA).

\section{Coffee samples}

A total of twenty-six coffee brew samples were acquired from different coffee vending machines in the Autonomous Community of Madrid during January-February (2013). The vending machines were located in public areas with a high traffic of people, such as hospitals, train and bus stations, higher education centers, etc. All automatic floor standing devices were different which very likely involved several types of brewing procedures, coffee origins and roasting degree, and coffee/water ratio for extraction. Automatic coffee machines were operated by ten of the most relevant companies dedicated to vending. Once acquired, fresh coffee samples were immediately stored in $100 \mathrm{~mL}$ double-sealed containers to prevent furan losses and refrigerated unopened at $4{ }^{\circ} \mathrm{C}$ until analysis. Volume of coffee beverage was measured.

\section{Measurement of $\mathrm{pH}$}


$\mathrm{pH}$ was measured in coffee brews by using a pH meter at ambient temperature (CG-837 pH meter, Schott, Mainz, Germany).

\section{Determination of dry weight}

Dry weight was determined gravimetrically. Two milliliters of each sample was accurately weighed and dried to constant weight in an oven at $102{ }^{\circ} \mathrm{C}$ for $4 \mathrm{~h}$. Percentage of dry weight was calculated with the following formula: [(weight of capsule with dry samples - weight of empty capsule) / (weight of capsule with fresh samples - weight of empty capsule) $] \times 100$.

\section{Browning determination}

Browning intensity was measured at $405 \mathrm{~nm}$ using a microplate reader. One milliliter of coffee brew was clarified with Carrez-I (potassium ferrocyanide 15\% w/v) and Carrez-II (zinc acetate 30\% w/v) solutions. Supernatant was diluted appropriately with water in order to obtain an absorbance reading less than 1.5 arbitrary units. All the measurements were made in triplicate. Results were expressed as absorbance units $/ \mathrm{mL}$ coffee.

\section{Determination of chlorogenic acids and caffeine}

Caffeine, total chlorogenic acids (CGAs) and 5-caffeoylquinic acid (5-CQA) were determined according the method described by Farah, Paulis, Trugo, and Martin (2005) and Fujioka and Shibamoto (2008). One milliliter of coffee brew was mixed with $7 \mathrm{~mL}$ of a $40 \%$ methanolic solution. After treatment with Carrez-I and Carrez-ll solutions, supernatant was filtered through a $0.45 \mu \mathrm{m}$ filter and the samples were then analyzed with HPLC. Quantification was conducted with a Shimadzu HPLC system (Kyoto, Japan) equipped with a LC-20 AD pump, a SIL-IOADvp autosampler, a CTO-IOASVP oven, and a SPD-M20A diode-array detector. The chromatographic separation was carried out on a Mediterranean Sea ODS-2 column $(250 \times$ $4.0 \mathrm{~mm}, 5 \mu \mathrm{m}$, Tecknokroma, Barcelona, Spain). The flow rate was $1.0 \mathrm{~mL} / \mathrm{min}$, and the injection volume was $10 \mu \mathrm{L}$. The mobile phase consisted of $0.5 \%$ acetic acid in water $(\mathrm{v} / \mathrm{v})$ (solvent $\mathrm{A}$ ) and methanol (solvent $\mathrm{B}$ ), and the gradient program was as follows: $0 \mathrm{~min}, 15 \% \mathrm{~B} ; 3 \mathrm{~min}, 15 \% \mathrm{~B} ; 35 \mathrm{~min}, 35 \% \mathrm{~B} ; 40 \mathrm{~min}, 60 \% \mathrm{~B} ; 48 \mathrm{~min}$, $80 \% \mathrm{~B} ; 50 \mathrm{~min}, 15 \% \mathrm{~B}$; and $60 \mathrm{~min}, 15 \% \mathrm{~B}$. The total running time was $60 \mathrm{~min}$, and chromatograms were further analyzed at $276 \mathrm{~nm}$ (for caffeine determination) and $325 \mathrm{~nm}$ (for 5-CGA determination). CGAs content in coffee was determined as the sum of caffeoylquinic acids, feruoylquinic acids, and dicaffeoylquinic acids by using 5-CQA as an external standard for calibration. The limit of quantification was set at 45.5 $\mathrm{mg} / 100 \mathrm{~mL}$ and $4.1 \mathrm{mg} / 100 \mathrm{~mL}$ for caffeine and CGAs analysis, respectively.

\section{Determination of HMF and furfural}

HMF and furfural were determined following the HPLC method described by Rufián-Henares, DelgadoAndrade, and Morales (2009). One milliliter of coffee brews was clarified with Carrez-I and Carrez-II solutions, supernatant was filtered through a $0.45 \mu \mathrm{m}$ filter and the samples were then analyzed with HPLC. A Shimadzu HPLC system, as described above, was used for quantification. The mobile phase was a mixture of acetonitrile in water $(5 \% \mathrm{v} / \mathrm{v})$ at a flow rate of $1 \mathrm{~mL} / \mathrm{min}$ under isocratic conditions through the analytical column Mediterranea Sea ODS-2 (250 $\times 4.0 \mathrm{~mm}, 5 \mu \mathrm{m}$, Tecknokroma, Barcelona, Spain). The total running time was $20 \mathrm{~min}$, the UV detector was set at $280 \mathrm{~nm}$ and $20 \mu \mathrm{L}$ of the extract was injected. HMF and furfural were quantified using the external standard. The limit of quantification was set at $0.5 \mathrm{mg} / 100 \mathrm{~mL}$ and $0.01 \mathrm{mg} / 100 \mathrm{~mL}$ for HMF and furfural, respectively.

\section{Furan exposure assays}


Furan levels were evaluated by duplicate in five different scenarios of coffee brew consumption in order to assess a realistic estimation of furan exposure.

Assay I. Coffee standing at room temperature for $5 \mathrm{~min}$ A coffee brew sample was acquired from a coffee vending machine and allowed to stand at room temperature for $5 \mathrm{~min}$. Aliquots $(5 \mathrm{~mL})$ were taken every 30 s simulating consumption. Temperatures were recorded throughout the 5 min (Datalogger, Delta OHM, Padova, Italy).

Assay 2. Coffee stirring for $30 \mathrm{~s}$ and standing at room temperature until $5 \mathrm{~min}$. A coffee brew sample was acquired from a coffee vending machine, stirred for $30 \mathrm{~s}$ and allowed to stand at room temperature until 5 min. Aliquots were taken every $30 \mathrm{~s}$. Temperatures were recorded throughout the $5 \mathrm{~min}$.

Assay 3. Coffee stirring for $5 \mathrm{~min}$ at room temperature Immediately after delivery from a vending machine, a coffee brew samplewas placed in a stirring device (Raypa, Barcelona, Spain) providing $150 \mathrm{rpm}$ in order to resemble the manual agitation with a spoon. Aliquots were taken every $30 \mathrm{~s}$. Temperatures were recorded throughout the $5 \mathrm{~min}$.

Assay 4. Coffee in sealed thermo for 8 h.A coffee brew sample was acquired from a coffee vending machine and immediately added to a sealed thermo and maintained up to $8 \mathrm{~h}$, simulating coffees consumed during the workday. Aliquots were taken every hour and temperatures were registered in each case.

Assay 5. Coffee refrigerated for one week $A$ coffee brew sample was acquired from a coffee vending machine and immediately stored in a double-sealed container and refrigerated unopened at $4{ }^{\circ} \mathrm{C}$. Aliquots were taken every day.

\section{Furan analysis}

Furan was determined by HS GC-MS according to the US FDA method (US FDA, 2004). Individual stock standard solutions of furan and furan- $\mathrm{d} 4$ were prepared by transferring each pure analyte via a microsyringe through the septum of $20 \mathrm{~mL}$ headspace vials containing methanol. Aqueous working standard solutions were individually prepared by the dilution of the stock solutions following the same procedure. The content of furan in the samples was determined by the standard addition method, where the amount of added furan in $\mathrm{ng}$ is represented versus the peak area ratio furan/furan- $\mathrm{d} 4(\mathrm{~m} / \mathrm{z} 68 / 72)$. The amounts of furan and furan$\mathrm{d} 4$ added to the test portion samples are based on the furan concentration in the coffee brews $(x 0)$, previously estimated.

Five milliliter aliquots of each coffee brew samples were added accurately into $20 \mathrm{~mL}$ headspace vials. 5-6 drops of potassium hydroxide solution (25\%)were spiked to each vial for increasing $\mathrm{pH}$ in order to avoid a forming of furan from precursors. Two sample vials were fortified with furan at levels of 0.5 times $(0.5 \times 0)$, one time $(1 \times 0)$ and two times $(2 \times 0)$ the estimated furan content in the samples. Three sample vials were not fortified with furan $(0 \times 0)$. Every vial was fortified with furan-d4 at levels of one time $(1 \times 0)$ the estimated furan content in the samples. All standards and samples were prepared at $4{ }^{\circ} \mathrm{C}$ in order to avoid furan losses. All the coffee brew samples were analyzed on the day of their acquisition.

Furan in the aliquots of coffee from the furan exposure assays was determined using an external calibration. In this case $5 \mathrm{~mL}$ of each aliquots of coffee were added into $20 \mathrm{~mL}$ headspace vials with spiking of potassium hydroxide solution and fortified only with furan- $\mathrm{d} 4$. Standard calibration was performed with vials containing 
$5 \mathrm{~mL}$ water and fortified with furan and furan- $\mathrm{d} 4$ in a similar way to the standard addition method described above.

\section{GC-MS conditions}

The determination of furan by headspace extraction gas chromatography mass spectrometry (HS-GC-MS) was performed using an Agilent 6890 gas chromatograph coupled to a 5973MSD Agilent mass spectrometer (Agilent, Waldbronn, Germany). The mass spectrometer was operated in positive electron impact ionization mode and quadrupole mass filter. The sample injection was carried out through a transfer line $\left(130^{\circ} \mathrm{C}\right)$ and constant pressure carrier gas ( $12 \mathrm{psi} \mathrm{He}$ ) connected to the GC inlet from a PerkinElmer TurboMatrix HS-40 (PerkinElmer, Massachusetts, USA) with preconcentration on Tenax TA Trap Mode (PerkinElmer, Massachusetts, USA).

Chromatographic separations were performed on a capillary HPPlot-Q column $(30 \mathrm{~m} \times 0.32 \mathrm{~mm} \times 0.20$ $\mu \mathrm{m})$ (J\&W Scientific, Agilent, Waldbronn, Germany). The oven temperature was programmed from 50 to $225{ }^{\circ} \mathrm{C}$ at $10{ }^{\circ} \mathrm{C} / \mathrm{min}$ and held for $12.5 \mathrm{~min}$. The injector temperature was $200{ }^{\circ} \mathrm{C}$ on splitless mode. Constant pressure rate of carrier gas was $12 \mathrm{~mL} / \mathrm{min}$ (Helium 99.995\%). Transfer line held at $230{ }^{\circ} \mathrm{C}$. Injection conditions were: needle $100^{\circ} \mathrm{C}$, oven $60^{\circ} \mathrm{C}$ for $20 \mathrm{~min}$, vial pressure $40 \mathrm{psi}$, trap from 50 to 250 ${ }^{\circ} \mathrm{C}$ and dry purge $5 \mathrm{~min}$.

Furan was detected by selected ion monitoring of the major ion at $\mathrm{m} / \mathrm{z} 68$ and confirmed by monitoring of the ion at $\mathrm{m} / \mathrm{z} 39$. Furan- $\mathrm{d} 4$ was detected by monitoring the equivalent ions at $\mathrm{m} / \mathrm{z} 72$ and $\mathrm{m} / \mathrm{z} 42$. Through the integrated response ratio for furan/furan $-\mathrm{d} 4(\mathrm{~m} / \mathrm{z}$ 68/72) and the amount of added standards, content of furan in the coffee brew samples was estimated.

\section{Validation of the method}

Themethod was validated by determining quality parameters. Linearity was studied by spiking appropriate amounts of furan and furan- $\mathrm{d} 4$ into the samples. Good linearity was obtained in the range of $3.7-500 \mathrm{ng} / \mathrm{mL}$. The recovery rate of furan spiked to the samples was usually between 90 and $115 \%$. The relative standard deviations (RSD) for the precision, repeatability and reproducibility of the analysis of furan in coffee were calculated as $3.7 \%, 0.9 \%$ and $3.4 \%$, respectively. The limit of detection (LOD) and the limit of quantification (LOQ) were $0.0 \mathrm{I}$ and $3 \mathrm{ng} / \mathrm{mL}$, respectively.

\section{Statistical analysis}

Statistical analyses were performed using Statgraphics Centurion XV (Herndon, VA, USA). Data were expressed as mean \pm standard deviation (SD). Analysis of variance (ANOVA) and the least significant difference (LSD) test were applied to determine differences between means. Differences were considered to be significant at $\mathrm{p}$ b 0.05 . Relationships between the different parameters analyzed were evaluated by computing Pearson linear correlation coefficients at the $p$ b 0.05 confidence level.

\section{RESULTS AND DISCUSSION}

\section{Characterization of the coffee brews}

It is known that the composition of brews depends on a number of variables such as green bean composition, roasting conditions, grinding, brewing procedure, extraction coffee/water ratio, water temperature, contact times and types of brewers (Petraco, 2005). In this study, the sampling scheme coveredmost representative brands of coffee vending machine on the Spanish market. Since the technology 
applied, design, coffee origin, intensity of roasting, extraction conditions, are expected to be largely different among devices, the coffee brew samples were further characterized.

Coffee brews were characterized by caffeine, chlorogenic acids, HMF, furfural content, and $\mathrm{pH}$, dry weight, and browning (Table I). Content on chlorogenic acids have been described to be $35-100 \mathrm{mg} / 100 \mathrm{~mL}$ per cup of home brewed Arabica coffee and 35-175 mg/100 mL per cup of Robusta coffee (Clifford, 1997). Similar ranges have been observed in coffee beverages analyzed in the present study $(28-149 \mathrm{mg} / 100 \mathrm{~mL})$, corresponding to $\sim 20 \% 5$-caffeoylquinic acid $(5-39 \mathrm{mg} / \mathrm{l} 00 \mathrm{~mL}$ ). $\mathrm{pH}$ of coffee brews ranged from 5.1 to 5.6 , and close to 4.95-5.59 as described by Fujioka and Shibamoto (2008) in brewed coffee. Samples showed a broader range for caffeine, varying from 67 to $205 \mathrm{mg} / 100 \mathrm{~mL}$. This range was within the levels from 50 to $380 \mathrm{mg} / 100 \mathrm{~mL}$ of coffee brew from medium roasted coffee reported by Farah (2012).

Considering that coffee beverages from a coffee vending machine are usually prepared with a ratio of $8 \mathrm{~g}$ of roasted coffee/ $/ 00 \mathrm{~mL}$ of water, the mean content of HMF in the coffee samples $(2.88 \mathrm{mg} / 100 \mathrm{~mL})$ was calculated to be $360 \mathrm{mg} / \mathrm{kg}$. This HMF content is in agreement with the range described by Arribas-Lorenzo and Morales (2010) in different samples of ground coffee (I 10 to $1734 \mathrm{mg} \mathrm{HMF} / \mathrm{kg}$ ). In a similar way, the mean content of furfural in the coffee samples $(0.05 \mathrm{mg} / 100 \mathrm{~mL})$ should correspond to $6.25 \mathrm{mg} / \mathrm{kg}$, respectively. This result is found within the range of $5.2-232 \mathrm{mg} / \mathrm{kg}$ reported by the World Health Organization (WHO, 1999) in roasted coffee.

\section{Furan levels in coffee brews}

Furan levels in the coffee brews acquired from coffee vending machines ranged from 10.8 to $262.4 \mathrm{ng} / \mathrm{mL}$, with a mean value of $171.4 \mathrm{ng} / \mathrm{mL}$ (Table 2, Fig. I). These furan concentrations were in agreement with those reported by Arisseto, Vicente, Ueno, Tfouni, and Toledo (20l I) in coffee brews (bl0-288 $\mu \mathrm{g} / \mathrm{kg}$ ), being also in line to the range showed by Zoller et al. (2007) $(46-199 \mathrm{ng} / \mathrm{mL})$, Kuballa, Stier, and Strichow (2005) $(57-115 \mathrm{ng} / \mathrm{mL})$, and EFSA (2009) $(100-230 \mu \mathrm{g} / \mathrm{kg})$ for coffee brews proceeding from vending or automatic machines. It is known that furan concentrations in coffee brews prepared in espresso or fully automatic machines are higher than those prepared with home coffee machines, by hand extraction or using French press coffee makers (Kuballa et al., 2005). In this sense, Altaki et al. (20II) described the furan content in espresso brews to be between 32 and $85 \%$ higher than that obtained with a home drip coffeemaker. Automatic coffee machines produce brews with higher levels of furan because a higher ratio of coffee powder to water is used, giving a lower dilution factor. Pressure applied in espresso machines is higher than that in home drip makers, and subsequently increases the extraction of furan from the coffee powder. In addition, a closed system facilitates furan retention (Altaki et al., 20I I; Crews \& Castle, 2007). On the other hand, coffee brew preparation in espresso machines requires less time than that required with home drip makers, which also decreases the furan losses during the brewing procedure (Farah, 20I2). This fact may explain the high furan levels in the coffee brews analyzed in the present study compared to furan concentrations reported in coffee obtained from home machines $(9-33 \mathrm{ng} / \mathrm{mL})$, manual machines $(17-24$ $\mathrm{ng} / \mathrm{mL}$ ) and French press machines (33-66 ng/mL) (Kuballa et al., 2005).

Furan content among samples was normalized for comparison taking into account the volume of beverage dispensed by each automatic machine. Volumes ranged from 55 to $100 \mathrm{~mL}$ per cup, which led to a total furan content ranging from 0.9 to $18.4 \mu \mathrm{g} / \mathrm{cup}$; the mean furan level in all the samples was $13.2 \mu \mathrm{g} / \mathrm{cup}$ (Table 2). It was investigated any correlation between chemical parameters measured in sample characterization and furan content. No correlations were observed except for furfural which showed a significant correlation $(r=0.4920, p=0.0125)$. 


\section{Furan stability in coffee brew}

As mentioned above, furan can be partially evaporated in the cup during consumption time since coffee brew is delivered at high temperatures (about $85{ }^{\circ} \mathrm{C}$ ) and consumers normally wait to drink after partial cooling (Guenther, 2012). Following these premises, several assays have been performed in order to study consumer handling on furan levels in a cup of coffee. Different samples of coffee brews acquired from the same vending machine were subjected to various practices simulating different scenarios of beverage consumption.

When coffee samples were kept at room temperature for 5 min (Assay I), furan content decreased by up to $25.7 \%$ of the level detected initially (time 0 ), which involved furan losses of $74.3 \%$ (Fig. 2). If this reduction is applied to the total furan content in each analyzed sample, it is calculated that coffee drinks kept at room temperature for $5 \mathrm{~min}$ would contribute an average of $3.4 \mu \mathrm{g} /$ cup (range: 0.2-4.7 $\mu \mathrm{g} /$ cup) (Table 2). Similar results were observed in Assay 2, where the coffee brews were stirred for $30 \mathrm{~s}$ (simulating sugar stirring) and kept at room temperature for $5 \mathrm{~min}$. In this case, furan losses of $64.3 \%$ were produced (Fig. 3), which would result in an average exposition of $4.7 \mu \mathrm{g}$ furan/cup in the coffee brews (range: $0.3-6.6 \mu \mathrm{g} / \mathrm{cup}$ ) (Table 2).

Several authors have carried out experiments with coffee samples exposed to the atmosphere at room temperature for various times, and different results have been reported. Zoller et al. (2007) observed furan losses of about 50\% after I h. Goldmann, Périsset, Scanlan, and Stadler (2005) described losses of 35\% after $4 \mathrm{~h}$ (levels decreasing from 22.4 to $8.0 \mu \mathrm{g} / \mathrm{kg}$ ), and Guenther et al. (2010) showed reductions of $25 \%$ after 30 min, assuming that losses of approximately 10\% occur within the first few minutes after the preparation of the cup of coffee. In a similar way, Kim, Lee, Park, and Lee (2009) reported that furan levels decreased by $24 \%$ after keeping a mug of instant coffee for I-5 min at room temperature without a lid. A similar experiment with brewed coffee showed that after $20 \mathrm{~min}$ at room temperature, furan levels decreased from 29.0 to $18.5 \mathrm{ng} / \mathrm{g}$ if the mug was kept without a lid and from 29.0 to $23.7 \mathrm{ng} / \mathrm{g}$ if the mug was closed with a lid. It was concluded that furan levels were significantly reduced when the samples were exposed to air after coffee brewing.

Former findings could explain the higher furan losses observed in the Assay 3 (stirring for $5 \mathrm{~min}$ ) compared with those from Assays I and 2. In Assay 3, furan decreased from $173.6 \mathrm{ng} / \mathrm{mL}$ (time $0 \mathrm{~s}$ ) to $10.7 \mathrm{ng} / \mathrm{mL}$ (time $300 \mathrm{~s}$ ), resulting in a furan loss of $93.8 \%$ (Fig. 4), probably because the stirring and the consequent higher exposition to air promoted furan volatilization. Applying this result to the different coffee brews, the mean furan exposure from the coffee drinks could be $0.8 \mu \mathrm{g} /$ cup (range: $0.1-1.1 \mu \mathrm{g} /$ cup) (Table 2). Lower furan exposure would be detected if coffee brews were stored for $8 \mathrm{~h}$ in a sealed thermo (Assay 4), which could simulate coffees consumed during the workday (mean: $0.3 \mu \mathrm{g} / \mathrm{cup}$, range: $0.02-0.5 \mu \mathrm{g} /$ cup). After this time furan levels decreased by up to $2.5 \%$ of the initial content (Fig. 5 ).

The last assay was to keep one coffee brew refrigerated for one week (Assay 5). Results have not been taken into account in estimations of Table 2 as we consider that such a long period is unusual for consumers. However, we performed this assay with the aim of estimating furan exposure for consumers who maintain coffee refrigerated at home and, furthermore, to know furan stability under refrigerated conditions in order to know the maximum suitable time for analysis of this compound. It is often recommended that coffee be stored in a refrigerator to maintain the desired aroma level, which may also condition the furan levels thus avoiding losses of this compound. In this context, Guenther et al. (2010) 
reported that the furan level of a pack of roast coffee decreased by $20-25 \%$ when was stored at room temperature whereas this remained almost constant when the pack was refrigerated for 7 days. In the present study, furan losses of $37 \%$ were observed after keeping coffee beverages refrigerated for one week (Fig. 6), which is indicative of the higher stability of furan at low temperatures. The decrease of the furan content in coffee during the first $24 \mathrm{~h}(23.4 \%)$ despite the fact that samples were refrigerated in doublesealed containers should be highlighted. These results should be considered when analyses of furan in food samples are carried out.

All these findings for furan stability in the coffee brew should be taken into account for a realistic estimation of exposure to furan. On one hand, the losses of furan produced by volatilization during the consumption time. On the other hand, the consumption habits including consumption over a long period of time after brewing. These scenarios may cause reductions in the furan exposure depending on the time and the conditions in which coffee is stored.

\section{Estimation of furan exposure from coffee}

As mentioned above, it has been suggested that coffee consumption may be the highest contributor to furan exposure from dietary sources for adults (EFSA, 2009; Mesías et al., 2012; Morehouse et al., 2008). EFSA (2009) estimated that the dietary intake of furan from coffee contributed between 43 and $79 \%$ of the total mean dietary exposure. Consistent with former findings, Mesías et al. (2012) identified coffee as the major contributor to furan exposure in the Spanish population, contributing $45.9 \%$ of the total furan intake. Furan exposure from coffee brews was estimated taking into account the range of concentrations observed in the present study. If we consider that the average coffee consumption is 599 cups per person per year as reported by the Spanish Coffee Federation (SCF, 2013), corresponding to 1.64 cups of coffee per person per day, then the mean daily furan intake would be $21.6 \mu \mathrm{g} /$ person/day (range: $1.4-30.2 \mu \mathrm{g} / \mathrm{person} /$ day). Assuming a mean body weight of $70 \mathrm{~kg}$ for an adult, the furan intake from coffee would range from 0.02 to $0.43 \mu \mathrm{g} / \mathrm{kg}$ b.w. $/$ day, resulting in a mean exposure of $0.31 \mu \mathrm{g} / \mathrm{kg}$ b.w. $/$ day. These results were close to the daily intake of furan from coffee estimated by EFSA (2004) $(0.5-0.6 \mu \mathrm{g} / \mathrm{kg}$ b.w./day). Lower estimations such as $0.15 \mu \mathrm{gg} / \mathrm{kg}$ b.w./day (Morehouse et al., 2008), 0.05-0.38 for males and 0.03-0.25 for females (Altaki et al., $20 \mathrm{II}$ ) and 0.299 and $0.177 \mu \mathrm{g} / \mathrm{kg}$ b.w./day (on average for men and women, respectively) (Liu \& Tsai, 2010) have been reported by other authors.

The maximum furan exposure estimated in our study is considerably lower than the value of $2 \mathrm{mg} / \mathrm{kg}$ b.w./day with no observable adverse effect level (NOAEL) established by the National Research Council for experimental animals (NRC, 2000), and $\sim 6.5$ times lower than the acceptable daily intake (ADI) estimated to be $2 \mu \mathrm{g} / \mathrm{kg}$ b.w./day (Kuballa et al., 2005). In this sense, it would be necessary a consumption of about 10 cups of fresh coffee brew per day or more than 30 cups of coffee brew after stirring (Assay 2) to reach the threshold for the acceptable daily intake.

\section{CONCLUSIONS}

Since coffee brew is considered one of the most important contributors to furan exposure in the diet for adults, it is necessary to know the furan levels in the final ready-to-drink beverage in order to obtain reliable estimations of the daily exposure to furan and to define potential strategies to reduce its intake if necessary. In this context, the amount of furan removed fromthe coffee beverage by volatilization during consumption time should be taken into account and represents a considerable reduction, nearly three times, of the initially calculated exposure from fresh coffee brew. It can be concluded that exposure to furan from coffee brew implies a low risk to human health. 


\section{CONFLICT OF INTEREST}

The authors have no conflict of interest.

\section{ACKNOWLEDGMENT}

This research was partly supported by the grants AGRI464-ANALISYC-II (CAM) and EU-FP7-265558 PROMETHEUS project. Authors thanks to Mr. M.A. Martinez (USTA) for technical assistance with GC/MS analysis.

\section{REFERENCES}

Altaki, M. S., Santos, F. J., \& Galceran, M. T. (20I I). Occurrence of furan in coffee from Spanish market: Contribution of brewing and roasting. Food Chemistry, 126, 1527-1532.

Arisseto, A. P., Vicente, E., Ueno, M. S., Tfouni, S. A., \& Toledo, M. C. (20II). Furan levels in coffee as influenced by species, roast degree, and brewing procedures. Journal of Agricultural and Food Chemistry, 59, 3| |8-3124.

Arribas-Lorenzo, G., \& Morales, F. J. (2010). Estimation of dietary intake of 5-hydroxymethylfurfural and related substances from coffee to Spanish population. Food and Chemical Toxicology, 48, 644-649.

Clifford,M. N. (1997). The nature of chlorogenic acids. Are they advantageous compounds in coffee? Proceedings of the 17th International Scientific Colloquium on Coffee (Nairobi) (Pp. 79-9I). Paris: ASIC.

Crews, C., \& Castle (2007). A review of the occurrence, formation and analysis of furan in heat-processed foods. Trends in Food Science and Technology, 18, 365-372.

EFSA (European Food Safety Authority) (2004). Report of the Scientific Panel on Contaminants in the Food Chain on provisional findings on furan in food. The EFSA Journal, 137, I.

EFSA (European Food Safety Authority) (2009). Results on the monitoring of furan levels in food. EFSA Scientific Report, 304, I-23 (http://www.efsa.europa.eu/en/scdocs/doc/304r.pdf accessed 20.03.2013).

EFSA (European Food Safety Authority) (2010). Scientific document: Update of results on the monitoring of furan levels in food. The EFSA Journal, 8, 1702.

FAO/WHO (Food and Agricultural Organization of the United Nations/World Health Organization) (2010). Summary and conclusions report of the seventy-second meeting of the Joint FAO/WHO Expert Committee on Food Additives. Rome: Joint FAO/WHO Expert Committee on Food Additives.

Farah, F. (2012). Coffee constituents. In Y. F. Chu (Ed.), Coffee. Emerging health effects and disease prevention (pp. 2I-58). lowa, USA: JohnWiley \& Sons, Inc. and the Institute of Food Technologists.

Farah, A., de Paulis, T., Trugo, L. C., \& Martin, P. R. (2005). Effect of roasting on the formation of chlorogenic acid lactones in coffee. Journal of Agricultural and Food Chemistry, 53, I505-15I3.

Fujioka, K., \& Shibamoto, T. (2008). Chlorogenic acid and caffeine contents in various commercial brewed coffees. Food Chemistry, 106, 217-221.

Goldmann, T., Périsset, A., Scanlan, F., \& Stadler, R. H. (2005). Rapid determination of furan in heated foodstuffs by isotope dilution solid phase micro-extraction-gas chromatography-mass spectrometry (SPMEGC-MS). Analyst, 130, 878-883.

Guenther, H. (20I2). Furan in coffee. In Y. F. Chu (Ed.), Coffee. Emerging health effects and disease prevention (PP. 307-318). lowa, USA: JohnWiley \& Sons, Inc. and the Institute of Food Technologists.

Guenther, H., Hoenicke, K., Biesterveld, S., Gerhard-Rieben, E., \& Lantz, I. (20I0). Furan in coffee: Pilot studies on formation during roasting and losses during production steps and consumer handling. Food Additives and Contaminants Part A, 27, 283-290. 
IARC (Internacional Agency for Research on Cancer) (1995). IARC monographs on the evaluation of carcinogenic risk to humans. Dry cleaning, some chlorinated solvents and other industrial chemicals, Vol. 63. (pp. 393-407) Lyon, France:World Health Organization.

Kim, T. K., Lee, Y. K., Park, Y. S., \& Lee, K. G. (2009). Effect of cooking or handling conditions on the furan levels of processed foods. Food Additives and Contaminants, 26, 767-775.

Kuballa, T., Stier, S., \& Strichow, N. (2005). Furan in kaffee und kaffeegetränken. Deutsche LebensmittelRundschau, I01, 229-235.

Liu, Y. T., \& Tsai, S.W. (2010). Assessment of dietary furan exposures from heat processed foods in Taiwan. Chemosphere, 79, 54-59.

Merritt, C., Bazinet, M. L., Sullivan, J. H., \& Robertson, D. H. (1963). Coffee aroma, mass spectrometric determination of volatile components from ground coffee. Journal of Agricultural and Food Chemistry, II, I52-I55.

Mesías, M., Guerra-Hernandez, E., \& Garcia-Villanova, B. (20I2). Estimation of exposure to furan in the Spanish population. International Journal of Food Science and Nutrition, 63, 16-22.

Morehouse, K. M., Nyman, P. J., McNeal, T. P., Dinovi, M. J., \& Perfetti, G. A. (2008). Survey of furan in heat processed foods by headspace gas chromatography/mass spectrometry and estimated adult exposure. Food Additives and Contaminants, 25, 259-264.

NRC (National Research Council) (2000). Spacecraft maximum allowable concentrations for selected airborne contaminants. Washington, DC: National Academy Press.

Petraco, M. (2005). The cup. In A. Illy, \& R. Viani (Eds.), Espresso coffee: The science of quality (Pp. 290298). Italy: Elsevier Academic Press.

Rufián-Henares, J. A., Delgado-Andrade, C., \& Morales, F. J. (2009). Assessing the Maillard reaction development during the toasting process of common flours employed by the cereal products industry. Food Chemistry, I14, 93-99.

SCF (Spanish Coffee Federation) (2013). http://www.federacioncafe.com/home.asp (accessed 10.02. 2013). US FDA (US Food and Drug Administration) (2004). Determination of furan in foods. Department of Health and Human Services. Rockville, MD: FDA, US Food and Drug Administration.

WHO (World Health Organization) (1999). Safety evaluation of certain food additives. International Programme on Chemical Safety. Geneva: World Health Organization.

Zoller, O., Sager, F., \& Reinhard, H. (2007). Furan in food: Headspace method and product survey. Food Additives and Contaminants, 24, S9I-SI07. 


\section{FIGURES AND TABLES}

Table I. Characterization of the coffee brew samples.

\begin{tabular}{|c|c|c|c|c|c|c|c|c|}
\hline No. & $\mathrm{pH}$ & $\begin{array}{l}\text { Dry weight } \\
\text { (\%) }\end{array}$ & $\begin{array}{l}\text { Browning } \\
\left(\mathrm{A}_{\text {s05 }} / \mathrm{mL}\right)\end{array}$ & $\begin{array}{l}\text { Caffeine } \\
(\mathrm{mg} / 100 \mathrm{~mL})\end{array}$ & $\begin{array}{l}\text { CGAs } \\
(\mathrm{mg} / 100 \mathrm{~mL})\end{array}$ & $\begin{array}{l}\text { 5-CGA } \\
(\mathrm{mg} / 100 \mathrm{~mL})\end{array}$ & $\begin{array}{l}\mathrm{HMF} \\
(\mathrm{mg} / 100 \mathrm{~mL})\end{array}$ & $\begin{array}{l}\text { Furfural } \\
\text { (mg/100 mL) }\end{array}$ \\
\hline 1 & 5.5 & 8.7 & 2.0 & 130.1 & 57.3 & 12.8 & 2.2 & 0.04 \\
\hline 2 & 5.6 & 1.8 & 2.1 & 149.6 & 76.9 & 17.3 & 2.2 & 0.04 \\
\hline 3 & 5.4 & 2.3 & 2.8 & 161.0 & 113.3 & 31.4 & 3.0 & 0.07 \\
\hline 4 & 5.4 & 2.3 & 3.0 & 198.7 & 148.8 & 39.4 & 4.4 & 0.06 \\
\hline 5 & 5.3 & 2.1 & 2.5 & 85.0 & 57.6 & 13.7 & 3.7 & 0.07 \\
\hline 6 & 5.4 & 3.0 & 4,4 & 136.8 & 129.3 & 31.6 & 5.5 & 0.09 \\
\hline 7 & 5.4 & 7.7 & 2.7 & 92.8 & 63.0 & 14.8 & 5.8 & 0.06 \\
\hline 8 & 5.4 & 1.9 & 2.2 & 112.9 & 66.4 & 15.3 & 1.2 & 0.07 \\
\hline 9 & 5.4 & 2.1 & 2.5 & 88.3 & 61.8 & 13.6 & 4.5 & 0.06 \\
\hline 10 & 5.5 & 1.2 & 1.3 & 75.9 & 48.3 & 10.0 & 1.9 & 0.04 \\
\hline 11 & 5.2 & 2.3 & 2.9 & 67.1 & 27.8 & 4.7 & 3.6 & 0.00 \\
\hline 12 & 5.4 & 1.4 & 1.8 & 116.3 & 87.7 & 23.7 & 2.8 & 0.04 \\
\hline 13 & 5.4 & 6.0 & 1.9 & 80.5 & 43.3 & 8.8 & 0.6 & 0.06 \\
\hline 14 & 5.6 & 1.9 & 2.0 & 153.7 & 54.6 & 11.0 & 0.9 & 0.03 \\
\hline 15 & 5.6 & 2.1 & 2.2 & 157.7 & 56.6 & 11.3 & 1.1 & 0.04 \\
\hline 16 & 5.5 & 1.6 & 1.6 & 110.1 & 56.9 & 12.9 & 1.6 & 0.05 \\
\hline 17 & 5.5 & 2.0 & 2.6 & 1322 & 61.5 & 14.1 & 3.8 & 0.05 \\
\hline 18 & 5.5 & 2.0 & 2.9 & 70.7 & 61.2 & 12.6 & 5.7 & 0.06 \\
\hline 19 & 5.6 & 1.7 & 1.6 & 118.1 & 52.3 & 11.4 & 0.6 & 0.05 \\
\hline 20 & 5.4 & 2.0 & 2.8 & 127.8 & 64.8 & 13.9 & 4.0 & 0.07 \\
\hline 21 & 5.7 & 2.6 & 3.2 & 184.6 & 62.5 & 13.0 & 1.6 & 0.05 \\
\hline 22 & 5.6 & 2.8 & 4.2 & 115.7 & 84.4 & 17.4 & 6.0 & 0.09 \\
\hline 23 & 5.1 & 4.4 & 5.8 & 154.0 & 109.5 & 25.9 & 5.0 & 0.01 \\
\hline 24 & 5.7 & 1.5 & 1.5 & 109.4 & 34.7 & 5.6 & 0.4 & 0.04 \\
\hline 25 & 5.3 & 3.3 & 4.9 & 205.2 & 127.8 & 29.9 & 1.5 & 0.13 \\
\hline 26 & 5.6 & 2.1 & 2.4 & 154.5 & 39.5 & 7.4 & 1.2 & 0.05 \\
\hline Mean & 5.4 & 2.8 & 2.7 & 126.5 & 71.1 & 16.3 & 2.9 & 0.05 \\
\hline
\end{tabular}

Table 2. Furan content in the coffee brews samples and estimations in each cup after the different assays.

Furan content in the coffee brews samples and estimations in each cup after the different assays.

\begin{tabular}{lcrllll}
\hline No. & $\begin{array}{l}\text { Furan } \\
\text { (ng/mL) }\end{array}$ & \multicolumn{1}{l}{$\mu$ g/cup } & $\begin{array}{l}\mu \mathrm{g} / \text { cup } \\
\text { (Assay 1) }\end{array}$ & $\begin{array}{l}\mu \mathrm{g} / \text { cup } \\
\text { (Assay 2) }\end{array}$ & $\begin{array}{l}\mu \mathrm{g} / \text { cup } \\
\text { (Assay 3) }\end{array}$ & $\begin{array}{l}\mu \mathrm{\mu g} / \mathrm{cup} \\
\text { (Assay 4) }\end{array}$ \\
\hline 1 & $219 \pm 0.3$ & $17.5 \pm 0.02$ & $4.5 \pm 0.01$ & $6.3 \pm 0.01$ & $1.1 \pm 0.00$ & $0.4 \pm 0.00$ \\
2 & $170 \pm 1.3$ & $13.6 \pm 0.10$ & $3.5 \pm 0.03$ & $4.9 \pm 0.04$ & $0.8 \pm 0.01$ & $0.3 \pm 0.00$ \\
3 & $175 \pm 2.5$ & $13.9 \pm 0.20$ & $3.6 \pm 0.05$ & $5.0 \pm 0.07$ & $0.9 \pm 0.01$ & $0.4 \pm 0.00$ \\
4 & $169 \pm 0.3$ & $10.1 \pm 0.02$ & $2.6 \pm 0.00$ & $3.6 \pm 0.01$ & $0.6 \pm 0.00$ & $0.3 \pm 0.00$ \\
5 & $194 \pm 3.9$ & $14.6 \pm 0.29$ & $3.8 \pm 0.08$ & $5.2 \pm 0.10$ & $0.9 \pm 0.02$ & $0.4 \pm 0.01$ \\
6 & $259 \pm 5.6$ & $14.3 \pm 0.31$ & $3.7 \pm 0.08$ & $5.1 \pm 0.11$ & $0.9 \pm 0.02$ & $0.4 \pm 0.01$ \\
7 & $200 \pm 2.7$ & $17.0 \pm 0.23$ & $4.4 \pm 0.06$ & $6.1 \pm 0.08$ & $1.0 \pm 0.01$ & $0.4 \pm 0.01$ \\
8 & $162 \pm 2.9$ & $13.7 \pm 0.25$ & $3.5 \pm 0.06$ & $4.9 \pm 0.09$ & $0.8 \pm 0.02$ & $0.3 \pm 0.01$ \\
9 & $210 \pm 6.0$ & $17.9 \pm 0.51$ & $4.6 \pm 0.13$ & $6.4 \pm 0.18$ & $1.1 \pm 0.03$ & $0.5 \pm 0.01$ \\
10 & $189 \pm 1.2$ & $11.3 \pm 0.07$ & $2.9 \pm 0.02$ & $4.1 \pm 0.03$ & $0.7 \pm 0.00$ & $0.3 \pm 0.00$ \\
11 & $24 \pm 0.7$ & $2.0 \pm 0.06$ & $0.5 \pm 0.02$ & $0.7 \pm 0.02$ & $0.1 \pm 0.00$ & $0.1 \pm 0.00$ \\
12 & $135 \pm 0.3$ & $13.5 \pm 0.03$ & $3.5 \pm 0.01$ & $4.8 \pm 0.01$ & $0.8 \pm 0.00$ & $0.3 \pm 0.00$ \\
13 & $209 \pm 1.4$ & $17.8 \pm 0.12$ & $4.6 \pm 0.03$ & $6.4 \pm 0.04$ & $1.1 \pm 0.01$ & $0.4 \pm 0.00$ \\
14 & $82 \pm 2.8$ & $8.2 \pm 0.28$ & $2.1 \pm 0.07$ & $2.9 \pm 0.10$ & $0.5 \pm 0.02$ & $0.2 \pm 0.01$ \\
15 & $144 \pm 5.4$ & $11.5 \pm 0.40$ & $3.0 \pm 0.11$ & $4.1 \pm 0.15$ & $0.7 \pm 0.03$ & $0.3 \pm 0.01$ \\
16 & $150 \pm 3.6$ & $12.7 \pm 0.31$ & $3.3 \pm 0.08$ & $4.6 \pm 0.11$ & $0.8 \pm 0.02$ & $0.3 \pm 0.01$ \\
17 & $145 \pm 0.3$ & $12.3 \pm 0.02$ & $3.2 \pm 0.01$ & $4.4 \pm 0.01$ & $0.8 \pm 0.00$ & $0.3 \pm 0.00$ \\
18 & $187 \pm 0.8$ & $13.1 \pm 0.05$ & $3.4 \pm 0.01$ & $4.7 \pm 0.02$ & $0.8 \pm 0.00$ & $0.3 \pm 0.00$ \\
19 & $195 \pm 3.5$ & $16.5 \pm 0.29$ & $4.3 \pm 0.08$ & $5.9 \pm 0.11$ & $1.0 \pm 0.02$ & $0.4 \pm 0.01$ \\
20 & $179 \pm 1.6$ & $15.2 \pm 0.14$ & $3.9 \pm 0.04$ & $5.4 \pm 0.05$ & $0.9 \pm 0.01$ & $0.4 \pm 0.00$ \\
21 & $262 \pm 2.7$ & $18.4 \pm 0.19$ & $4.7 \pm 0.05$ & $6.6 \pm 0.07$ & $1.1 \pm 0.01$ & $0.5 \pm 0.00$ \\
22 & $242 \pm 0.3$ & $17.0 \pm 0.02$ & $4.4 \pm 0.01$ & $6.1 \pm 0.01$ & $1.0 \pm 0.00$ & $0.4 \pm 0.00$ \\
23 & $11 \pm 0.1$ & $0.9 \pm 0.01$ & $0.2 \pm 0.00$ & $0.3 \pm 0.00$ & $0.1 \pm 0.00$ & $0.0 \pm 0.00$ \\
24 & $168 \pm 1.1$ & $15.1 \pm 0.10$ & $3.9 \pm 0.02$ & $5.4 \pm 0.03$ & $0.9 \pm 0.01$ & $0.4 \pm 0.00$ \\
25 & $163 \pm 1.9$ & $9.8 \pm 0.11$ & $2.5 \pm 0.03$ & $3.5 \pm 0.04$ & $0.6 \pm 0.01$ & $0.2 \pm 0.00$ \\
26 & $214 \pm 3.0$ & $14.9 \pm 0.21$ & $3.8 \pm 0.05$ & $5.3 \pm 0.08$ & $0.9 \pm 0.01$ & $0.4 \pm 0.01$ \\
Mean & $171 \pm 59.8$ & $13.2 \pm 4.35$ & $3.4 \pm 1.12$ & $4.7 \pm 1.56$ & $0.8 \pm 0.27$ & $0.3 \pm 0.11$ \\
\hline & & & & & &
\end{tabular}

Values are mean \pm SD. 
Figure I. Box plot for furan concentrations in the coffee brews acquired from the coffee vending machines.

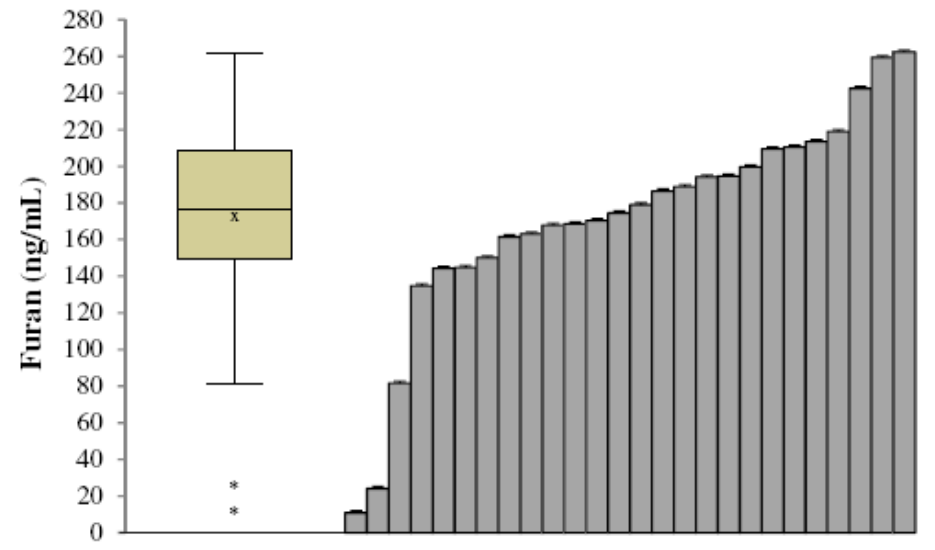

Figure 2. Furan content in a coffee brew standing at room temperature for $5 \mathrm{~min}$.

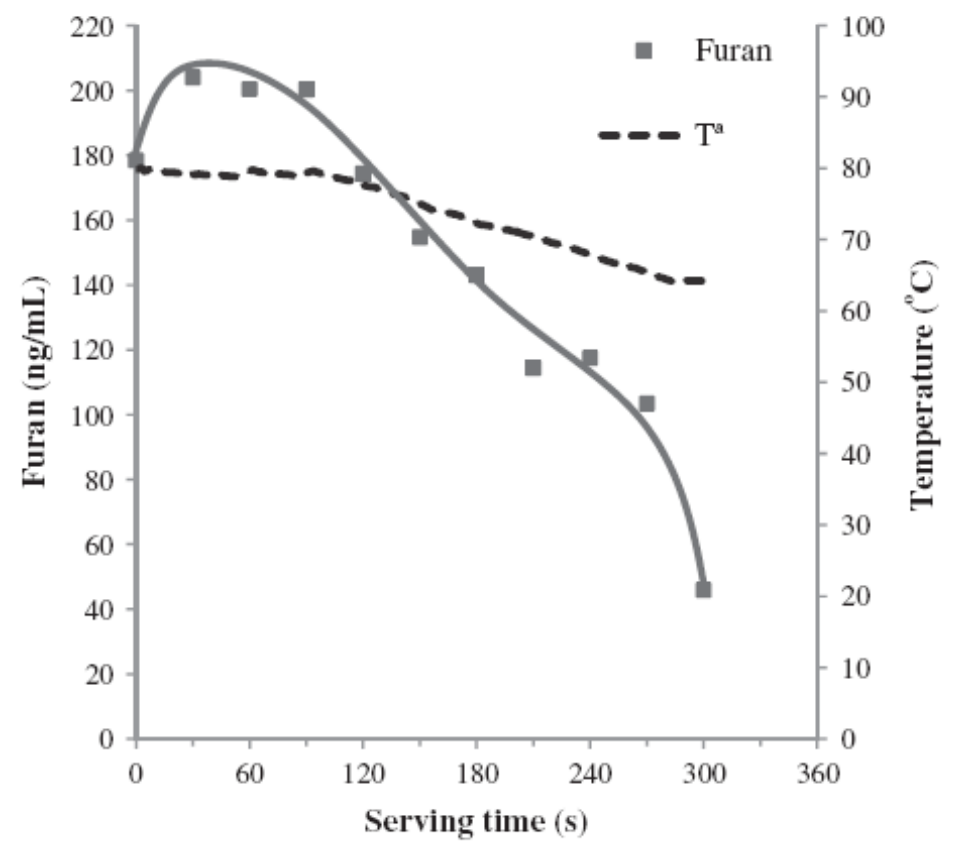


Figure 3. Furan content in a coffee brew stirring for $30 \mathrm{~s}$ and standing at room temperature until $5 \mathrm{~min}$.

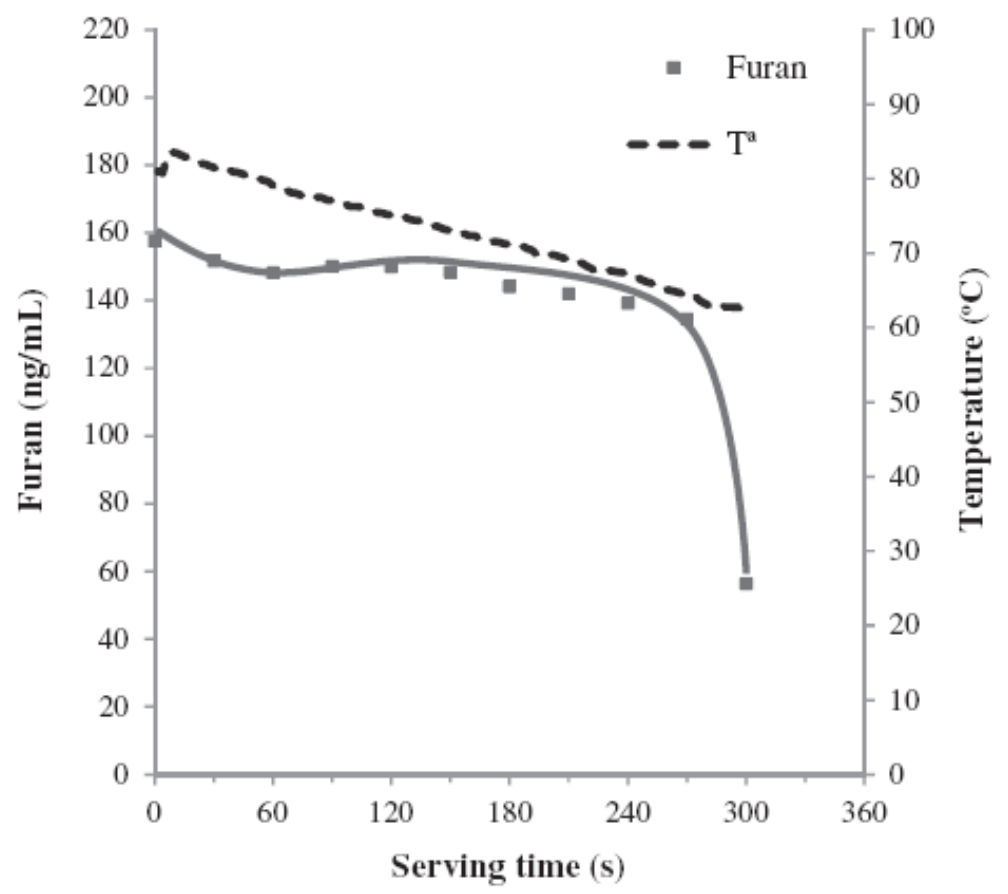

Figure 4. Furan content in a coffee brew stirring for $5 \mathrm{~min}$ at room temperature.

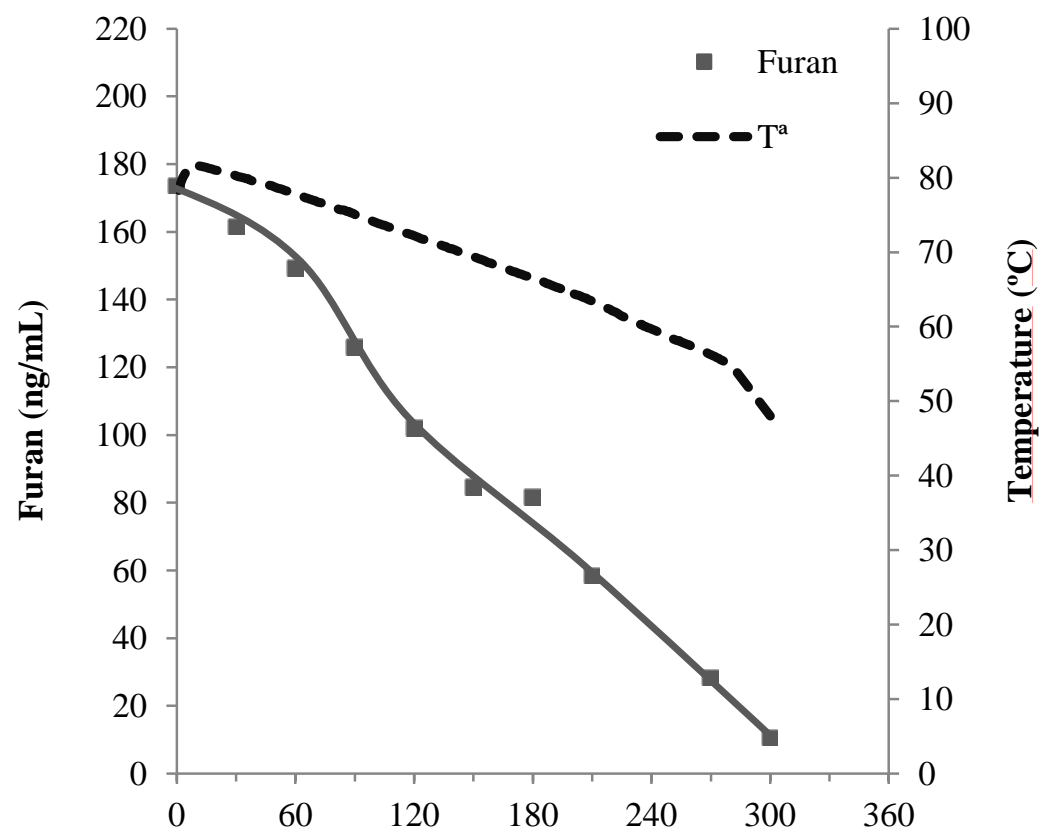

Serving time (s) 
Figure 5. Furan content in a coffee brew kept in a sealed thermo for $8 \mathrm{~h}$.

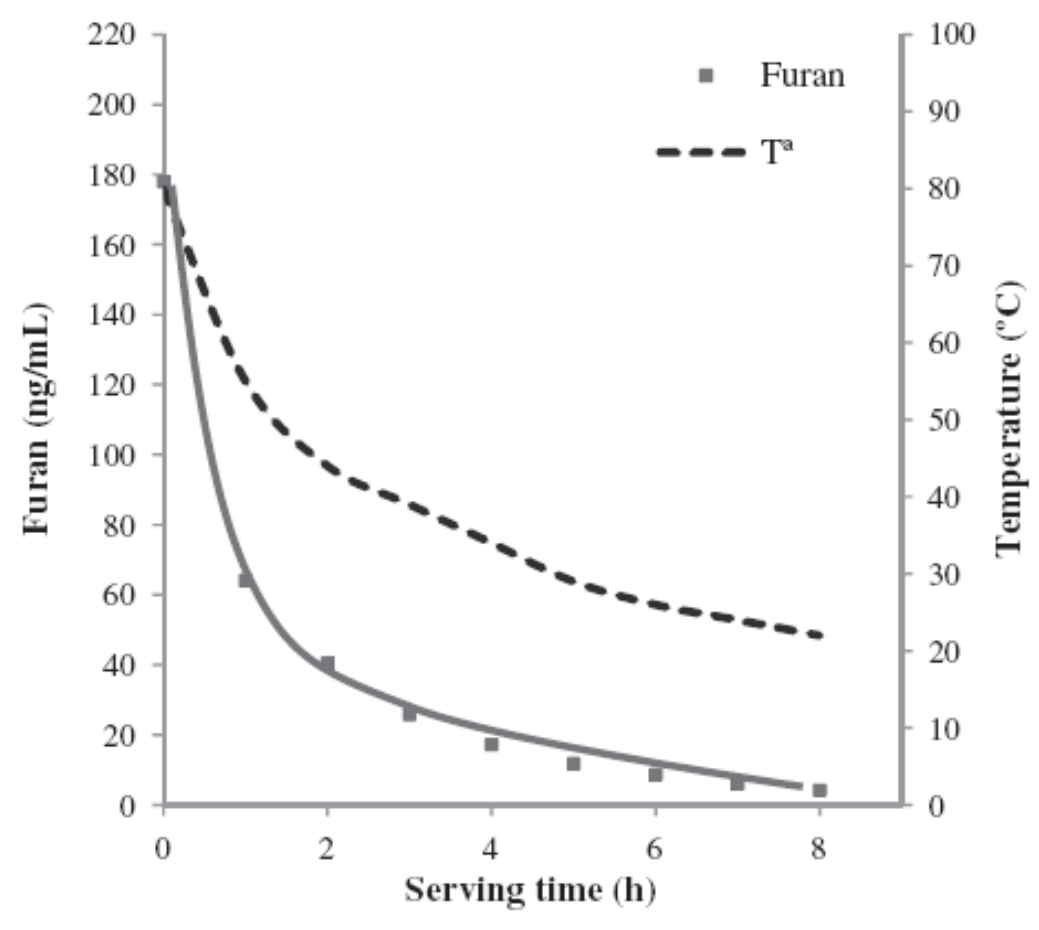

Figure 6. Furan content in a coffee brew refrigerated for one week.

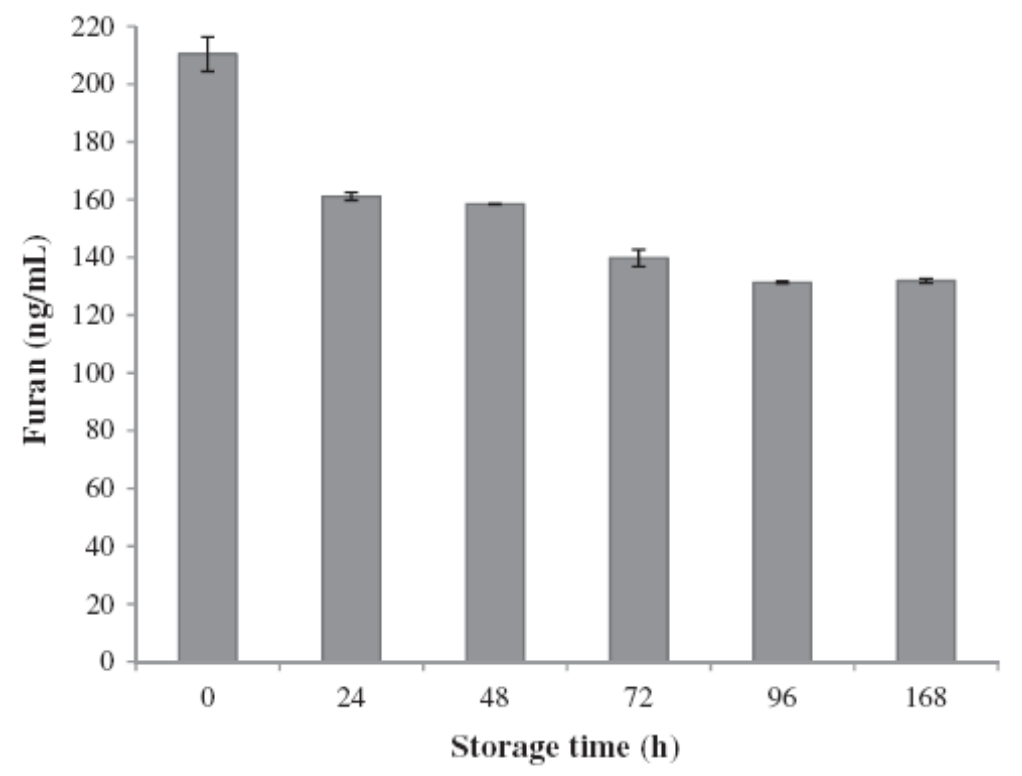

